\title{
On the Cultivation of Famous Teachers in Rural Areas
}

\author{
Fangchun Chi \\ General education center of Xijing UniversityXijing Road No. 1, Changan District, \\ Xijing University, Xi'an, Shaanxi province 710123 \\ 710123, 15249277083, chifangchun2006@126.com
}

\section{Keywords: Famous Teachers; Teaching; Rural areas}

\begin{abstract}
Famous teachers in rural areas greatly contribute to popularizing culture and education in rural areas. This paper analyzes the connotation, characteristics, standards and literacy of famous teachers in rural areas, as well as factors influencing their growth, professional development, development rules, training stages, training projects, training strategies, selection index systems and the establishment of awards for famous teachers in rural areas.
\end{abstract}

\section{Connotation and Characteristics of Famous Teachers in Rural Areas}

Connotation of Famous Teachers in Rural Areas. Famous teachers in rural areas are dedicated good teachers respected by students in cultivation, personality and achievements and they can deliver wonderful classes. They are the perfect combination of reputable scholars and teachers, students' mentors, teachers' models, the school's brand and local celebrities ${ }^{[1]}$ with outstanding achievements and great influence in the field of education ${ }^{[2]}$. Famous teachers in rural areas are teachers' self-creation of knowledge-oriented personality and personalized knowledge ${ }^{[3]}$. They are scholars and education experts. Scholars' spirit, extraordinary tolerance, independent personality, broad vision and profound knowledge constitute to famous teachers' style and temperament. Famous teachers have educational wisdom and spirit and unparalleled teaching advantages ${ }^{[4]}$.

Characteristics of Famous Teachers in Rural Areas. The characteristics of famous teachers in rural areas lie in professional originality, practical growth, scientific certification and the service of training famous teachers ${ }^{[5]}$. They firmly believe that they are worthy of their reputation, accessible, approachable, tireless in teaching with unique style, outstanding performance and extensive influence ${ }^{[6]}$. As the backbone and foundation of rural education, famous teachers stand for local literacy with the spirit of seeking truth. They are independent, willing to sacrifice, dare to doubt, indifferent to wealth and fame and they enjoy teaching ${ }^{[7]}$. As local famous teachers, they have the regional, dynamic and developmental characteristics ${ }^{[5]}$. Besides, they have high academic attainments, noble academic quality and teaching art as well as the spirit of innovating teaching results and sacrificing for students. Rural education experts or expert teachers have the following features: Career-oriented teachers are highly dedicated with thorough understanding of teaching and learning. They do not lack love for teaching. Artistic teachers have language talent and performance ability. Research-oriented teachers regard teaching as a research object, research content and method. The method to study teaching and learning is inseparable from research. The teaching of famous teachers in rural areas is rich in cultural taste, wisdom and personality. Their teaching advantages are embodied in which the teaching is profound, unique, extensive, inspiring and witty, These teachers have the skill to adapt to local customs and educational environment of rural areas [8].

\section{Standards and Quality of Famous Teachers in Rural Areas}

Standards of Famous Teachers in Rural Areas. First of all, famous teachers in rural areas should have noble and outstanding moral characters, profound and good humanistic qualities. They should love education, indifferent to fame and wealth. They should be steady, hardworking, diligent and rigorous with strong sense of responsibility and mission. They should rectify the learning 
atmosphere, set themselves as examples, teach and care for students with noble teaching morality. Secondly, standing at the three-inch podium, famous teachers in rural areas should spread civilization and knowledge to students and constantly work hard for students to master basic theoretical knowledge and cultivate students' innovative spirit and practical ability. Thirdly, famous teachers in rural areas have broad and profound academic attainments. They have been engaged in teaching for a long time with unique teaching results. Fourthly, famous teachers in rural areas have advanced education concept, their teaching philosophy is in line with the times' requirements. They pay attention to teaching reform practice, master scientific teaching methods, use advanced teaching means and flexible teaching methods to arouse students' interest in learning and research. In addition, famous teachers in rural areas undertake the mission of discipline construction and training teachers. They pay attention to the development of their respective disciplines, study and discuss discipline development rules and trends. They actively get involved in revising teaching plans and constructing emerging curriculum. They consciously guide and help young teachers ${ }^{[9]}$.

Quality of Famous Teachers in Rural Areas. Famous teachers in rural areas have professional quality and accomplishment. They are dedicated at work with firm belief in education and career goal that will gradually progress upwards. They constantly strive to become stronger, attach importance to carrying out effective and feasible educational research with unique knowledge structure. They value time with unique teaching style and charming personality ${ }^{[10]}$. The best way to learn is to learn from the best. The famous teachers in rural areas play an important role in training talents in underdeveloped rural areas. In order to improve the educational level in rural areas, it is necessary to have a considerable number of famous teachers and managers who can recognize famous teachers ${ }^{[11]}$.

\section{Growth of Famous Teachers in Rural Areas}

$\mathrm{Yu} \mathrm{Yi}$ proposed the famous teacher training experience: deep insight, high academic degree, great potential and teamwork ${ }^{[12]}$. The development of famous teachers is essentially the highly-developed process of teachers as professional educational talents as well as the innovation process of constantly surpassing themselves. The growth of famous teachers in rural areas is featured by being complicated, cyclic and phased. There are critical periods and breakthrough periods. Opportunities should be seized during growth. The complexity of the growth process is characterized by the uncertainty and non-linearity of the teacher's growth. It is not necessary to grow into a teaching teacher. The direction of teacher growth is no single and linear. The entry stage is the key period of the growth of rural teaching teachers. Plateau platform stage is the breakthrough period of rural teacher growth. Rural teacher growth is difficult and twists and turns of the complexity of the professional development process. It is the process of continuous progress. The level of individual growth of rural teachers is related to the number of years of service, depending on whether the quality conditions can achieve the overall improvement and leapfrogging. It also depends on whether the external mechanism can effectively help rural teachers to shorten the entry into the critical period as soon as possible, break through the development of plateau occupational development of dangerous period and to maintain the level of maturity should be. A rural teacher from the beginning of the development of rural teachers for the development of qualified teachers, grow into the backbone, sublimation of well-known teachers, and even education experts, famous teachers. The ultimate goal is by no means unattainable. To achieve their own needs, the times call for rural teacher look forward to rural education fire heritage and famous generation ${ }^{[13]}$. The noble education belief is the starting point of the growth of rural teaching. Persistent professionalism is the growth point of rural teaching teacher growth. Strong social responsibility is the growth point of rural teacher. School loyalty is the difficulty of rural teacher growth ${ }^{[5]}$.

Factors Influencing the Growth of Famous Teachers in Rural Areas. Influencing factors include intrinsic key factors and external critical factors. Key figures are influencing the development of rural teaching masters, including key figures in the family, key figures from preaching and key figures after teaching ${ }^{[14]}$. The impacts of education include educational writers or film and television works, teacher education art, key character dialing, student approval, key 
people's support and help incentives publicity and other forms. The reasons for the impact of multiple both role. The role of return ${ }^{[15]}$. Teachers need a relaxed, free school environment and highlight the knowledge of the personality of the school style ${ }^{[3]}$. The development and growth of rural teachers is in the interaction between the main body of teachers and the surrounding environment. Through the various activities of the main body to achieve is the dynamic and changing the cycle of interactive development process. Famous teacher is the inevitable pursuit of the success of teachers and meeting a high level of self-realization needs. The key factors are teacher personality and career ideal. The dynamic factors are lifelong learning and innovation ability. The core factor is to learn and dilute the reflection. Rural teaching teacher growth external factors are good academic atmosphere, moderate external pressure, old teacher sending the band and the students good feedback ${ }^{[16]}$. The factors influencing the development of rural teaching teachers have their own factors and non-self factors. Professional factors, ideals, beliefs, personal interests, professional social awareness, professional role consciousness and self-development and other factors are the factors that affect the development of teachers. Occupational social perceptions include professional subjective understanding, professional social comparison, professional self-awareness and educational self-efficacy. Professional role awareness includes career role knowledge, career role division and professional role success experience ${ }^{[17]}$.

Professional Growth of Famous Teachers in Rural Areas. Rural culture is the cradle for the growth of famous teachers in rural areas. History, culture and researching culture and traditional are the soil for the growth of famous teachers in rural areas. Autonomous development the space for professional development of rural teacher teaching, learning, practice, reflection and research is the fundamental path of professional development of rural teacher ${ }^{[18]}$. Rural teacher is the product of subjective factors and external environmental factors. Individual subjective factors include the love of education, the love of students, the desire for achievement and diligence habits, the ability to educate people, education research in the hands of practical experience, the law of education and their own quality of continuous research.

Reflection and Adjustment. The external environmental factors refer to the objective conditions provided by the state and the school for the teachers. The social atmosphere is conducive to the teacher's devotion to the education of the teacher. The material condition is conducive to the teachers to carry out the teaching and scientific research. The good campus atmosphere conducive to the teacher's growth, such as the school relaxed and strong academic atmosphere, solidarity and friendly interpersonal relationships and recommending the talents can be the campus culture ${ }^{[1]}$.

Development of Famous Teachers in Rural Areas. The development of rural teachers is in a certain support environment. They actively and autonomously continue to enhance their professional quality and achieve the highest teacher standard dynamic continuous process. The development of rural teacher has characteristics of independent effort, environmental support, development continuity, professional promotion and arrival peak. The development of rural teacher is the development of the whole stage. It is a dynamic process of continuous generation with full stage, multiply way and complexity. The first to fifth stages are: brewing period, preparation period, adaptation period, maturity and fame. The sixth stage is the peak period. The peak period is the peak of the development of rural teacher, education and teaching consummate, profound knowledge, energetic, strong, artistic skills, fame and strong charm. Rural teacher to appreciate the true meaning of education, realize the education of the mystery, experience the fun of education, enjoy the happiness of education is easier to produce "teacher effect". The seventh and eighth stages are the extension and the remaining heat. The ninth stage is the period of influence. The influence of rural teacher is due to its noble behavior, the pursuit of perseverance, love for students, unique insights, creative work, learning and tireless and outstanding performance as a teacher. ${ }^{[19]}$ The development path of rural teacher includes reading, education practice, reflection, research and learning from others. Reading includes the subject cultural foundation, physiology, pedagogy, psychology, practical knowledge and philosophical books. Reflection to the teacher on the stairs arrives at the top of the teacher. They can think about themselves three times every day and write diary of teaching. Learn from others includes apprentices, lectures, seminars and competitions ${ }^{[20]}$. 
Rules for the Growth of Famous Teachers in Rural Areas. In an ecological community, each species has a different time, space and functional location than other species, and has the temporal and spatial positioning which suits itself best. If the species is formed and has a niche that is suitable for its own survival and development, it can weaken the vicious competition with other species and ensure the order and stability of the biosphere. Rural education teacher growth always needs a period of time and a most suitable environment for development. In this environment, give full play to their own advantages can come to the fore of their professional growth leap to a new and rapid development platform to create an environment conducive to the development of teachers to diversify the teacher development space ${ }^{[21]}$. Rural teachers meet the needs of the times, participate in educational practice, cultivate talent, sum up educational experience and innovative education theory ${ }^{[2]}$.

\section{Training of Famous Teachers in Rural Areas}

Teachers should keep pace with the times, timely update knowledge and improve teaching quality and level. The school should strengthen the effectiveness of training, systematically define the concept, content, principles and methods of teacher training and turn the training of theoretical knowledge into the ideological. Political and business comprehensive training focus on teachers' ideological and political quality and business quality.

The Unity of Theory and Practice. Practical training methods are mentoring training, practice reflective, case training, seminars training and remote training ${ }^{[22]}$. Teacher training needs academic mental health. we must create a humanistic atmosphere, strengthen the system construction and pay attention to teaching, scientific research, management and construction.

Stages of Training Famous Teachers in Rural Areas. Teacher project will help teachers build and improve the quality of teaching. Teacher training at all stages of its training strategy includes the basic adaptation of teaching work to mastery of teaching knowledge and skills, the novice to become a skilled stage, the excellent teaching staff to teaching and research combined to become a teaching teacher stage ${ }^{[23]}$.

Projects to Train Famous Teachers in Rural Areas. Teaching teacher project has a huge effect. It should be implemented through the "rural teaching teacher project", cultivate a group of rural teaching teacher and drive the construction of rural teachers ${ }^{[1]}$. Combined with the actual situation in rural areas, the teacher assessment highlights the characteristics of the rural areas of teaching teachers to build a vibrant vitality. Highlight the rural characteristics of the teacher training. For rural areas schools, students disciplines and curriculum characteristics take targeted construction countermeasures, creating a rich regional characteristic and excellent teaching level. Teaching performance is outstanding in rural teacher team ${ }^{[24]}$. Rural teacher training project construction in the regional, selection methods needs to have operational. First, highlight the geographical advantages and rural characteristics. Second, identify the breakthrough with the city school teaching teacher candidates. Third, carefully analysis competitive characteristics to find the advantages of the specific countermeasures. Highlight the particularity of the selection and training of micro-individual. For the teaching teacher, selecting the core standard to find a breakthrough: the teaching reform as the starting point and the rural area disadvantage as the advantage of the selection strategy ${ }^{[25]}$.

Strategies to Train Famous Teachers in Rural Areas. Provide teachers with fair chances for development, full freedom of education to overcome utilitarianism. Respect teachers' demand for professional development, ease their pressure during growth and establish scientific teacher evaluation system.

\section{Selection of Famous Teachers in Rural Areas}

The construction of rural teachers is growing day by day, and there are also problems that cannot be ignored: the decline of teachers' professional ethics, the lack of corresponding attention and the decline of teaching quality. It is necessary to improve the quality of teaching and improve the 
quality of teachers' needs. ${ }^{[26]}$ It is the need to improve the quality of teachers' professional ethics. Encourage the rural teachers to explore the law of education and teaching. The use of heuristic teaching will cultivate students' social responsibility, practical ability and creative spirit into the entire teaching work in leading teaching content, methods and means of reform, innovative curriculum materials and teaching mode. Reasonable teaching echelon and other aspects to make outstanding achievements ${ }^{[27]}$. Comprehensively understand and grasp the connotation, change the evaluation index system, and deeply analyze the connotation and characteristics of the index system of the teaching teacher evaluation over the years ${ }^{[28]}$. Establishment of rural teaching teacher awards. Ignore rural teachers in the selection of teachers. The selection of teachers should be adjusted to increase the number of rural school candidates or the other to develop a set of rural school teachers for the selection of indicators system, so that a group of higher teaching level of rural teachers selected by demonstrating the role of radiation improve the overall quality of teachers and rural education personnel training quality ${ }^{[29]}$, the construction of a reasonable structure, excellent quality of the teaching staff ${ }^{[30]}$.

\section{References}

[1] Ling Shuiming, Ge Gaofang. On the Featured Value and Growth Conditions of Famous Teachers [J]. Journal of XinYu College.2004(4):41-43.

[2] Wang Hanping, Zhou Hongmin. Analysis of the Growth Rules of Famous Teachers [J]. Journal of Jiangxi Radio and TV University. 2003(4):43-44.

[3] Shao Junfeng. Reflection on Famous Teachers [J]. Journal of Dalian University. 2004(3):77-79.

[4] Chen Lie. On Famous Teachers at Colleges and Universities [J]. Journal of Fujian Normal University (Philosophy and Social Sciences edition). 2004(6):131-134.

[5] Xia Xinjun. Teachers in the Background of Specialization - An Interview with Teacher Xia Xinjun of Yangzhou Education Institute [J]. Educational Theory and Practice, B.2007(9):4-7.

[6] Wang Yuxun. On the Characteristics of Famous Teachers [J]. Jiangxi Education and Scientific Research. 2006(6):3-5.

[7] Ding Sanqing. Famous Teachers and University Spirit [J]. Chinese Journal of Agricultural Education. 2006(1):9-11.

[8] Yang Xinlin. The Basic Connotation and Requirement of Famous Teaching Teachers in Colleges and Universities [J]. Journal of Beijing Institute of Machinery Industry. 2007(6):78-82.

[9] Li Jian. Standard of Famous Teachers, Coaching Paradigm [J]. Chinese University Teaching. 2003(9):20.

[10] Wang Ying. On the Quality of Successful Instructors [J]. Contemporary Educational Science. 2007(1):40-43.

[11] Huo Chuntao, Li Yuanfeng. The Role of Famous Teachers and Celebrities in Talent Training [J]. Innovative Culture. 2005(3):232-235.

[12] Yu Yi. My Opinions on Training Famous Teachers. Jiangsu Education Research (Practical Edition). 2008(2):4-5.

[13] Fang Jianhua. Interpreting the Successful Life Track of Famous Teachers [J]. Journal of Jiangsu Institute of Education (Social Science Edition). 2004(3):1-7.

[14] Wang Ying. Key Figures are External Key Factors Influencing the Development of Famous Teachers [J]. Journal of Tianjin Academy of Educational Science. 2006(5):45-47. 
[15] Wang Ying. On the Forms and Causes of Key People 's Influence on the Development of Famous Teachers [J]. Journal of Linyi Normal College.2006(4):93-96.

[16] An Analysis of the Factors Affecting the Growth of Famous Teachers - A Case Study of Professor Yu Hongzhen, the First National College Teacher Award Winner [J]. Higher Education in Coal. 2006(6).107-108.

[17] Wang Ying. An Analysis of the Factors Affecting the Development of Teachers [J]. Journal of Tianjin Normal University (Elementary Education Edition). 2005(3):12-15.

[18]Fang Jianhua. Soil Space and Path of Teachers' Professional Development - Taking Jiangsu Teachers as an Example [J]. Contemporary Educational Science.2007(3-4):52-55.

[19] Wang Yuxun. The Concept and Stage of the Development of Famous Teacher [J]. Contemporary Educational Science. 2005(20):18-20.

[20] Wang Yuxun. On the Common Mode of Teacher's Independent Development [J]. Contemporary Educational Science. 2008(22):35-38.

[21] Tang Zhengang, Jin Lijiu. On the Principles and Methods of the Study of Teacher 's Growth [J], Education Guide. 2011(1):70-73.

[22] Du Hua, Zhou Hong. Research on the Effectiveness of Teachers' Training in Casting Teaching [J]. Higher Education in Coal. 2006(1):98-100.

[23] Chen Min. A Study on the Strategies of Periodic Training of Teachers in Colleges and Universities [J]. Higher Education in Coal.2004 (4):68-70.

[24]Zeng Maolin. On the Nationality of the Teaching Masters in the Ethnic Minority Areas [J]. Journal of Guangxi Teachers Education University (Philosophy and Social Sciences Edition). 2007(1):31-34.

[25] Wang Yi, Zeng Maolin. A Study on the Cultivation Strategy of National Teaching Masters in Guangxi Colleges and Universities - Taking Three National Teaching Masters as Examples [J]. Higher Education Forum. 2008(6):45-48.

[26] Guizhi Xiang, Xiong Chu Cai. The Necessity of Appraining College Teachers [J]. Journal of Hunan Agricultural University (Social Science Edition).2008(3):9-10.

[27] Ministry of Education's Decision on Awarding Award-Winning Famous Teachers in the 2nd Session of Teachers at Institutions of Higher Education [J]. China's University Teaching. 2006(10):4-5.

[28] Wang Lirong. The Change and Tendency of the Appraisal Index System of Teaching Teachers in Colleges and Universities [J]. Education in Heilongiiang Province.2007(10):84-85.

[29]He Jing. An Analysis and Reflection on the Selection of Teaching Masters in Colleges and Universities [J]. Vocational Education Newsletter. 2007 (2):34-36. [30] Wang Shuling. A Study on the Social Support of Rural Teachers' Professional Development under the Background of New Urbanization [J]. China's Adult Education. 2106(20):131-134 